\title{
The Bacterial Flora of the Slime and Intestinal Contents of the Haddock (Gadus aeglefinus).
}

\author{
By \\ Mary Macfarlane Stewart, B.Sc. (Agr.), Ph.D., \\ Torry Research Station, Aberdeen.
}

THE surface of most fish is covered with a coating of slime which increases in amount after death when the fish is held at room temperature or stowed in ice. The slime has been examined by Dr. Ingvaldsen of the Prince Rupert Station who has found that 3 c.c. of this material contain $33.348 \mathrm{mg}$. of nitrogen of which 11.9 per cent is amino-nitrogen. It is poor in carbohydrates, but along with the mineral salts contained in seawater it appears to provide an excellent medium for bacterial growth. In the fresh fish, the slime is clear, of mucous consistency, and shows comparatively few organisms in stained films, but in fish which are not quite fresh the slime appears to be increased in amount, is opaque and increased in consistency. With increasing age the slime becomes yellowish and evil-smelling, and stained films show an enormous increase of bacteria. In the early stages of the work attempts were made to correlate the number of organisms in the slime with the age of the fish by making bacterial counts, but owing to the irregular distribution of the slime over the surface of the fish and the difficulty of making homogeneous suspensions the results were not very satisfactory, although gross changes were readily detected. A survey of the literature on the subject of fish bacteriology revealed little knowledge of the nature of the organisms usually present on the surface of freshly caught fish, and it seemed desirable to examine this question in detail as a preliminary to work on the problems of spoilage. The results which are presented in this paper are the records of a series of systematic observations upon the nature of the organisms found in the surface slime and intestinal contents of one species of freshly caught salt-water fish. The haddock was chosen as the most suitable fish for investigation because it could be obtained with regularity throughout the year. The experimental work was carried out at the Torry Research Station, Aberdeen, of the Department of Scientific and Industrial Research, and under the personal supervision of Professor J. Cruickshank, Department of Bacteriology, Marischal College, Aberdeen. Twenty-two fish have been examined in detail for the nature of the 
surface flora. Most of the fish were line caught in the inshore waters off the coast of Aberdeen, but in a few cases trawled fish from deeper waters were used. On these occasions a fish from the top of the trawl net which had presumably not come into contact with contaminated surfaces, e.g. the deck of the boat, was selected. The fish was removed from the hook or from the trawl net with the minimum of handling and transferred to a sterile tin box which was not opened until delivered in the laboratory. In all cases the time which elapsed between the catching of the fish and the arrival of the fish at the laboratory did not exceed six hours.

In a few cases samples of slime were taken by rubbing a sterile cottonwool swab over the surface of the fish at the time of catching. The swab was replaced in its sterile glass container and conveyed to the laboratory. This method was designed to avoid contamination of the surface of the fish by the fisherman's hands. The same fisherman practised both methods and there was no appreciable difference in the results. For the majority of the isolations hormone agar made from horse heart or ox muscle was used. An agar made from fish muscle was employed on several occasions, but it was more troublesome to prepare and did not produce better or more luxuriant growth, and its use was discontinued.

On arrival at the laboratory a sample of the surface slime was taken on a sterile platinum loop and the material plated out on a series of plates. These were incubated aerobically, at first both at $22^{\circ} \mathrm{C}$. and $37^{\circ} \mathrm{C}$., but as growth at the higher temperature was always scarce, the lower temperature only was used in subsequent isolations. Anaerobic cultures were not made.

For the examination of the intestinal contents twelve additional fish were used. The ventral surface of the fish was sterilised by the application of a germicidal dye mixture $(0.5 \%$ crystal violet and $0.5 \%$ brilliant green in $50 \%$ alcohol), or by flaming with alcohol, and an incision was made along the middle line with sterile instruments. A loop of intestine containing undigested material was cut out and placed in a sterile Petri dish ; upper or lower intestine was taken indiscriminately. The intestine was opened longitudinally with a sterile scalpel and a sample of the contents withdrawn with a platinum loop. Owing to the small number of organisms present in the contents of the intestine of fish, as compared with mammals, it was unnecessary to make dilutions of the material for primary plating and often considerable masses of the contents were spread in order to obtain good growth. Incubations were made aerobically at $22^{\circ} \mathrm{C}$.

In a few cases where the intestine was empty and the mucus only was plated out, little or no growth was obtained and no isolations were made. Even where undigested food material was present, the number of organisms was always strikingly less than in mammalian intestine. 
After twenty-four hours' incubation little or no growth was apparent on plates inoculated with slime or intestinal content and it was only after an interval of three days or more that colonial differences were sufficiently marked to allow of the isolation of different types. In a series of preliminary investigations it was found that air organisms and moulds were frequent contaminations on plates which were incubated for long periods, and in the subsequent work all plates were prepared and inoculated in a deep glass box, open on one side only, which was thoroughly sterilised before use. It was found generally that a platinum loopful of slime spread over three plates gave abundant growth and that as a rule well-separated colonies were obtainable from the second or third plates of the series. Subcultures of colonies were made on agar slopes from the various types and after a considerable period of incubation these were carefully examined for purity. It was frequently necessary to replate the cultures as they were often found to be contaminated with slow-growing types.

The morphological characters of the organisms were examined from agar slopes and from broth cultures and the appearances on agar and potato and in broth and gelatin were noted. Records were made of their behaviour in various carbohydrates and in litmus milk, and of their power to produce indole and acetyl-methyl-carbinol and to reduce nitrate. In the study of certain of these cultural characters, long periods (up to ten weeks) were given before the results were noted.

In addition to the information gleaned from the literature, referred to later, Bergey's Manual of Determinative Bacteriology (1) was found to be useful as a standard of reference, and the terminology employed in this paper is more or less that used by him. The identification of these organisms with types already described has been found to be difficult or impossible, partly owing to the inadequate descriptions given in the literature of many water, sea-water, and soil organisms, and partly owing to the absence of distinguishing features or reactions in many of the organisms encountered.

A notable feature of the plates made from slime was the variation in the number of colonies of chromogenic organisms. In some cases these were few or absent, in others they constituted a considerable percentage of the total number of colonies. Orange or lemon-yellow colonies were most common, but variations from a pale flesh to brown colour were seen. It was found in the course of the subsequent examination of these chromogenic organisms that little or no dependence could be placed on the intensity of the pigment as the colour varied markedly in any one type with age and with the nature of the medium. Colonies of a pure culture might show all degrees of variation in intensity of pigment on the same medium. Further, bacteria, which appeared to be in all other respects 
alike, might show in culture on agar or on potato marked differences in pigment formation.

With regard to the non-chromogenic organisms the colonies were usually moist and shining, and varying most definitely in opacity, but the absence of distinctive features made it extremely difficult to recognise different types from the colonial appearances alone. As a result there was much repetition in the course of the work, and many strains of the same organism were submitted to examination. In contrast to the slime the intestinal contents showed few or no chromogenic colonies.

\section{Surface Flora.}

Of the 247 cultures isolated from haddock slime of which descriptions are appended, 140 were non-sporing bacilli corresponding in their general characters with the group Achromobacter (Bergey). He describes these as " rods, small to medium in size, occurring principally in water and soil. Form no pigment on agar or gelatin but may produce a brownish growth on potato. Cultural characters variable. Some species form acid in simple sugars, others are without action on carbohydrates. Motile or nonmotile. Gram-negative." Although no accurate quantitative estimations of the relative proportions of various genera in the slime were attempted the relative numbers of Achromobacteria to other organisms in the primary cultures suggested strongly that this type preponderates in the surface slime of the haddock. Of the organisms which have been classed as Achromobacter for convenience fifteen different types may be recognised on the basis of biochemical activities, of which two are of especial interest, one, because it includes seventy per cent of the total number of cultures, and the other, because of its close similarity to an organism isolated from living halibut in the Pacific Ocean and described in detail by Harrison (2).

Cultures belonging to the first of these two types have been isolated from all but one of the fish examined, and were present in large numbers in practically all the samples. Ninety-seven cultures have been examined. Morphologically small non-motile coccobacilli occurring in pairs and short chains, they are distinct from any other organisms isolated. In their cultural and biochemical activities they are very similar, differing only in their actions on glucose and on nitrate. If importance is placed on these reactions they can be divided into four sub-groups or strains according as they ferment glucose or reduce nitrate.

Agglutinating sera were produced in rabbits against two cultures of this type, but although these sera were active against the homologous organisms there was no cross agglutination, and other members of the type were not affected. The absence of pigment and the general 
"inertness" were in agreement with the group Achromobacter, but they have not been identified with any of the fifty-six named types of Achromobacter in Bergey's Manual, nor have they been described in any available literature.

Organisms of the second type have been isolated from three samples of slime only. They show marked proteolytic properties as demonstrated by their power to liquefy coagulated ox serum and differ markedly from the other types in this respect. The characters of this type are in complete agreement with those of Achromobacter pellucidum described by Harrison from halibut slime. This worker, however, claims to have demonstrated a filterable or " symplastic " stage of this organism, but attempts to repeat this work with the haddock cultures have so far failed.

Of the remaining thirteen types nine correspond closely to types described in Bergey's Manual, but are not identical with these. The other four types show sufficient resemblance to the Achromobacter to be placed in this group, but cannot be identified with any organisms described by other workers.

As regards frequency of occurrence in the cultures the next most important genus is Micrococcus, forty cultures of which have been examined. Seven types were recognised of which five were pigmented. The cocci were similar to the common air organisms and to those described by Harrison which he obtained from halibut, but differ in certain particulars. One type (19) liquefied coagulated ox serum. On two occasions cocci, showing motility of a rotatory character, have been isolated from slime. Motile cocci are seldom encountered in general bacteriological work, but Harrison and Fellers (3) report having isolated them repeatedly from halibut and from salmon respectively. The organisms isolated in the course of this work differ from Rhodococcus agilis, as described by Harrison, in the colour of the pigment produced and in fermentation reactions.

Of the remaining organisms Flavobacteria and Pseudomonas were the only types occurring in significant numbers. Of the former, twentyseven cultures were isolated. In contrast to the Achromobacteria, in which a multiplicity of types was met with, the types of Flavobacteria were relatively constant. Only five types were found in the twentyseven cultures. These were similar in most respects to water organisms listed by Bergey and to types isolated by Harrison. It is worthy of note that whereas the majority of Flavobacteria types are Gram-negative, four of the five types were Gram-positive. In general, the Flavobacteria were more active biochemically than the Achromobacteria, producing some change in litmus milk and in most cases liquefaction of gelatin. They were, however, less active in carbohydrate media than the Micrococci. One of the types (29) liquefied coagulated ox serum.

Organisms of the genus Pseudomonas occurred on five fish only, and 
were never numerous. They were identical in all respects with the types fluorescens, viscosa, and convexa (Bergey).

With regard to coliform organisms it is of interest that organisms of mammalian intestinal type have not been encountered, and that only four cultures belonging to the genus Aerobacter have been met with. Two of these were Aerobacter aerogenes and two Aerobacter cloaca. As all the fish were taken close to the three mile limit off the coast of Aberdeenshire, the absence of coliform types is noteworthy.

In the course of the work it was found that when agar plates of the primary cultures were examined in a dark room colonies might be found which were luminous. The "phosphorescence" or luminescence of fish kept under certain circumstances is a well-known phenomenon, and various types of luminescent organisms have been described from time to time in sea-water and on marine animals. Nevertheless, no mention is made of the presence of these bacteria in the literature of other workers who have made systematic observations on the bacteriology of fish. The isolation of these organisms from plates crowded with other bacteria is difficult, as the luminosity of the colonies is their only distinguishing feature, and the presence of other organisms in large numbers appears in some way to interfere with their growth or with the production of light on agar plates. Probably for the same reason it has been found that fish which have been kept for some time so that they have become brightly luminous do not readily give cultures from which luminous organisms can be isolated. In the case of fresh fish, however, there is less difficulty, and separated luminous colonies may be encountered which are readily picked off and purified. Not infrequently when the cultures of slime failed to give luminous colonies the cultures of intestinal contents of the same fish did so. These organisms show considerable variation in morphology, but in young culture they were for the most part Gram-negative bacilli or coccobacilli. Eighteen cultures have been obtained and have been studied. It is hoped to give a separate communication upon the characters of this particular group.

In view of the work of Gee (4) and others who have described sporebearing organisms of the subtilis-mesentericus group (genus Bacillus), particular attention was paid throughout this work to the detection of spore-bearers. These were never isolated from slime although they were met with in the intestine.

Of minor interest because of the infrequency of occurrence, it may be mentioned that yeasts were isolated on two occasions, and that two organisms producing a bright red pigment and agreeing in general characters with the genus Serratia were obtained. One of these cannot be placed among the types described in Bergey's Manual. 


\section{Intestinal Flora.}

Forty-six cultures have been isolated. As in the case of the slime, members of the genus Achromobacter preponderated in every sample, and in several instances were present almost in pure culture. Five different types of Achromobacter were distinguished, of which the coccobacillary type, already referred to as occurring in slime, was the only one common to both sites. The other four types were not identical with any of the Achromobacter found in the slime.

Flavobacteria were present in one sample only. These differed slightly from the Flavobacteria isolated from slime, and from an organism isolated by Harrison from halibut. Aerobacter cloaca was obtained on one occasion.

In contrast to the results obtained from the examination of slime, spore-bearing organisms were present in small numbers in almost every sample of intestinal content. The characters of these have been found to agree in almost every respect with those of marine spore-bearing organisms published by Newton (5).

The occurrence of luminescent organisms in the intestine has already been referred to.

Reed and Spence (6), in the case of haddock from the mouth of the St. Croix River, Nova Scotia, in a quantitative examination of eleven samples of slime and thirty-four samples of intestinal content found Proteus types by far the most common organism $(70 \%)$ in the intestinal contents, with Achromobacter $4 \cdot 4 \%$, Pseudomonas $8 \cdot 7 \%$, Flavobacter $5 \cdot 6 \%$, Aerobacter $4 \cdot 6 \%$, Bacillus $5 \cdot 7 \%$, and others $1 \%$. In the slime the corresponding figures were Proteus 18\%, Achromobacter 23\%, Pseudomonas $22 \%$, Flavobacter $8 \%$, Bacillus $24 \%$, Micrococci $4 \%$. The striking feature of these results is the constant occurrence in the intestinal contents of the Proteus type which has not once been encountered in this investigation either in the slime or intestinal contents of haddocks from the North Sea. In their comparison of individual fish there was marked irregularity with regard to the occurrence of the various genera, e.g. Proteus types were frequently abundant in the slime of some fish and absent in others caught under similar circumstances. In contrast to the results recorded here, Achromobacteria were not found regularly in the intestinal contents and were absent occasionally from the slime. In the case of the intestine the same irregularity of occurrence was shown by the other groups of organisms.

It is noteworthy that Pseudomonas types were found in considerable numbers in all the samples of slime examined by these workers, and frequently in the intestinal content, whereas Harrison failed completely to isolate this organism from the slime of fresh halibut in spite of special 
attempts to do so. In the present work this group was encountered in six samples of slime only. As the colonial appearances of this group are distinctive, its presence in the material examined was not likely to be overlooked. This organism has been encountered frequently in bacteriological examinations of decomposing fish (Fellers; Harrison, Perry, and Smith (y); and Harrison), and as it has active proteolytic properties and may be active in spoilage it is important to ascertain the source. It is a common water type, is almost constantly present in samples of ice in which fish are preserved, and is thus likely to contaminate samples of slime unless stringent precautions are taken to avoid extraneous organisms.

Reed and Spence also report the constant presence of the genus Bacillus in slime, whereas in this investigation this genus, although almost constantly present in the intestine, was never encountered in the slime. Gee also found spore-bearers in slime, the other organisms being Proteus, Pseudomonas, and Diplococcus types, but it is remarkable that he did not encounter Achromobacteria. He has also found spore-bearing organisms in the muscle of living fish, and attributes to them much of the spoilage which results on keeping, whereas other workers have found fresh muscle to be sterile.

A comparison of this work with the work of various Canadian and American investigators (Obst, 8; Hunter, 9 ; Fellers; Harrison, Perry, and Smith; and Sanborn, 10) who have made bacteriological studies of salmon, halibut, sardines, and other fish with reference to spoilage, is difficult, as in many cases the samples were taken indiscriminately from slime, muscle, and intestine and from fish in various stages of decomposition. It is sufficient to say that most of the groups mentioned above have been met with.

\section{CONCLUSIONS.}

1. The bacterial flora of the slime and intestinal contents of North Sea haddocks has been investigated, and two hundred and ninety-three cultures in all have been examined in detail.

2. The most common organisms in both sites were Achromobacteria, and of these several types were usually present. One type in particular predominated which has not hitherto been described by other workers.

3. Organisms of the genus Micrococcus were found frequently in slime but not in the intestine.

4. Flavobacteria were present irregularly in the slime samples, but were encountered in only one sample of intestinal contents.

5. Pseudomonas types were found in the slime of a few fish, and only in small numbers. They were not met with in the intestine. 
6. Spore-bearing organisms were never met with in the slime, but were present in most samples of intestinal contents in small numbers.

7. Luminescent organisms were present irregularly in the slime and in the intestinal contents.

I wish to express my deep indebtedness to Professor J. Cruickshank for his constant help and advice throughout the work.

\section{BIBLIOGRAPHY.}

1. Bergey, D. H. 1926. Manual of Determinative Bacteriology. 2nd Edition. William and Wilkins, Baltimore.

2. Harrison, F. C. 1929. The Discoloration of Halibut. Canadian Jour. of Res., I, 214.

3. Fellers, C. R. 1926. Bacteriological Investigations on Raw Salmon Spoilage. Univ. of Washington, Pub. in Fisheries, I, 157.

4. Gee, A. H. 1927. Bacteria Concerned in the Spoilage of Haddock: Preliminary Report. Contrib. Canadian Biol. and Fish., III, 349.

- 1930. Bacteria Concerned in the Spoilage of Haddock. III. Further Observations on the Flora of Live Fish, ibid. V, 433.

5. Newton, D. E. 1924. Marine Spore Forming Bacteria. Contrib. Canadian Biol. New Series, I, 379.

6. Reed, G. B., and Spence, C. M. 1929. The Intestinal and Slime Flora of the Haddock: Preliminary Report. Canadian Biol. and Fish., IV, 257.

7. Harrison, F. C., Perry, H. M., and Smith, P. W. P. 1926. The Bacteriology of Certain Sea Fish. Report 19, Canadian Nat. Res. Council.

8. Овsт, M. M. 1919. A Bacteriological Study of Sardines. Jour. Inf. Dis., XXIV, 158.

9. Hunter, A. C. 1920. Bacterial Decomposition of Salmon. Jour. Bact., V, 353.

1920. Bacterial Groups in Decomposing Salmon, ibid., 543.

10. Sanborn, J. R. 1930. Certain Relationships of Marine Bacteria to the Decomposition of Fish. Jour. Bact., XIX, 375. 


\section{ACHROMOBACTER.}

Morphology

Coccobact pairs or short chains. Gram negative.
Rods, majority small, occas- ional long forms. Gram negative.

Rods, medium to swollen at one or both ends. Gram-negative. Rods, ${ }^{4}$ medium
size, singly and
in chains, some
fi l a m en t s.
Gram-negative. Rods, medium Gram-negative.

\section{Motility}

Agar Slope
Whitish, translucent to semi opaque, slight ly raised, moist and smooth. a. b. c. d.

*Glucose

Lactose

Saccharose

Mannite

Dulcite

Indole

*V.P.

Nitrate

Litmus Milk

Potato

‡Gelatin
Slime

Intestine

Related to

- - -

$\begin{array}{llll}- & - & - & - \\ - & - & - & -\end{array}$

- - -

$\stackrel{+}{+}+$
+ faint, late.
Slowly acid.
$+$$$
-
$$
becoming
No change. Scant and glisten-
ing.

Scant and glistening.

White,

\section{Ach. fermenta-}

tionis (Chester)

Bergey et al.

* Glucose $+=$ acid

$\begin{aligned} \text { * V.P. } & =\text { no acid } \\ & =\text { Voges Proskauer test }\end{aligned}$ long, a few

\section{Translucent to semi - opaque, slightly raised, smooth shining surface.}

\section{Creamy, semi- opaque, slight. ly raised, moist, smooth and shining.}

\section{Translucent to semi - opaque, slightly raised, shining.} g listening, limited, becom.

ing fawn. moist, No growth.

No change.

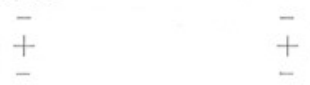

6 length, majority long, slender, slightly curved, others swollen and filamento us. Gram negative.

Whitish, raised, opaque, tending to "flow" down slope. Later becomes transparent with buff to b r o w n opaque parti cles.

parti-

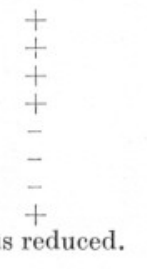

Litmus reduced.

Litmus reduced, milk peptonised, serum brown and slimy.

\section{Seant, whitish and No growth.} glistening.
Rods, vary in 
Morphology

7.

Rods, medium length, rather stout, rounded ends. Gramnegative.

Motility

Agar Slope

Whitish, slightly
raised, opaque,
moist, surface
smooth and
shining.

Gluçose

Lactose

Saccharose

Mannite

Dulcite

Indole

V.P.

Nitrate

Litmus Milk

Gelatin

Slime

Intestine

Related to

$-$

$-$

Coagulation, marked shrinkage of clot and separation of whey, complete reduction except at surface which is pink.

Moist, raised, coming brown.

\begin{abstract}
8.
\end{abstract}
Rods, short and stout, rounded ends, singly, in pairs. Sometimes short chains. Gramnegative.

Whitish, slightly raised, semiopaque, moist, surface smooth and shining.

- or faintly + late.

- or faintly + late. pinkish fawn be-

Pale cream, opaque, moist and shining, discoloured.

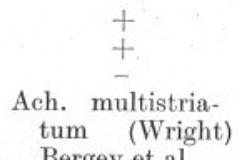

Ach. mu

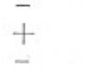

tum (Wright)

Bergey et al.

tum (Wright)

Bergey et al.

\section{9.}

length, mediu m Rods, medium size,

stout, rounded

ends, occur

singly. Gram-

negative.

Whitish, semi-
opaque, flat,
moist, smooth
surface, becomes
transparent.

\begin{tabular}{lr}
\multicolumn{2}{c}{${ }^{+}$} \\
Raised, semi- \\
opaque, moist, \\
pink - brown \\
tinge at foot of \\
slope, surface \\
smooth and \\
shining.
\end{tabular}

$$
\begin{aligned}
& + \\
& - \\
& - \\
& -
\end{aligned}
$$

Alkaline and peptonised first at surface, later throughout, litserum yellow.

Fawn, spreading, wet, opaque.

Sepia - brown,
moist, shining
and opaque,
potato disshining.

Litmus completely reduced, peptonring at surface.

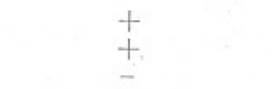
coloured. Wright) Bergey et al. (Wright) Bergey et al. rounded ends.

11.

Rods, rather long and slender,

occur singly.

Gram-negative. mus reduced,

No growth.

Whitish, slightly raised, translucent, moist, surface smooth and shining. isation, green

No change.

No change. medium length, slender, rounded ends, occur singly. Gram-negative.

Whitish, semiopaque, tending to "flow" over slope, moist, smooth and shining.

$+$

Ach. geniculatum

Ach. geniculatum

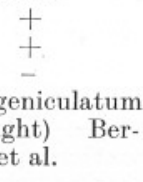

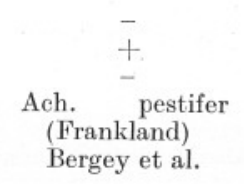

Fawn to pinkish, opaque, slightly raised.$$
+
$$

Ach. venosum (Vaughan) Bergey et al.
}

虫 


\section{ACHROMOBACTER.}

Morphology

13.

Rods, medium length, slender, rounded ends. Gram-negative.

Motility

Agar Slope

Flat, translucent, moist, tending to spread, surface smooth and shining.

Glucose

Lactose

Saccharos
Mannite

Dulcite

Indole

V.P.

Nitrate

Litmus Milk

Potato

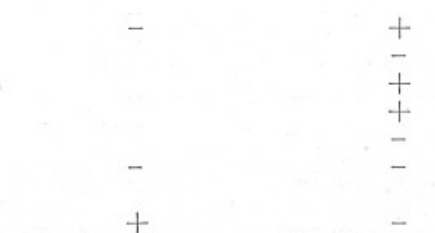

Slowly becomes No change.

alkaline.

Fawn, wet, glistening, tending to spread.

Gelatin

Slime

Intestine

Related to
14.

Rods, short and slender. Gramnegative.

rounded ends,

Luxuriant, whitish, translucent, flat, spreading, surface smooth and shining.

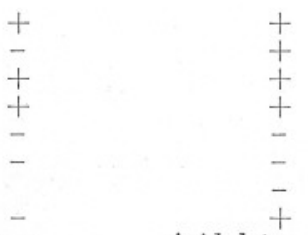

Scanty, white and shining.

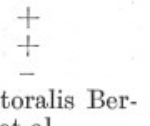

gey et al.
15.

Rods,

occur singly.

Gram-negative.

16.

Rods, short, many degenerate and with small areas failing to stain. Gram-negative.

Flat, ${ }_{\text {moist, }}^{+}$smooth moist, smooth white becoming pinkish.

Acid, late.

+
+
+
+
-
-
+

Opaque, slightly No growth.

raised, surface smooth and shining, white becoming pinkish.

$$
+
$$

Flat, transparent, uneven surface, growth in condensation water reddish brown.
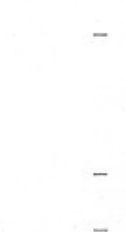

o change.

$$
\text { - }
$$

Rods, short and

Creamy, flat, semi-

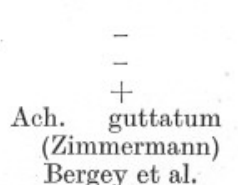

17. stout, occasional swollen fil amentous forms, many have small areas failing to stain. Gramnegative. opaque, moist, surface smooth and shining.

18.

Rods, short and stout, some swollen irregular forms, many show marginal staining. Gramnegative.

\section{Creamy, ${ }^{+}$semi-} opaque, slightly raised, moist, surface smooth and shining, becomes trans lucent.

+
-
-
-
-
+

No change organism does not grow well.

No growth.

+
-
-
-
-
-
+
ge.

$\begin{array}{cc}- & + \\ - & - \\ \begin{array}{c}\text { Ach. pestifer } \\ \text { (Frankland) }\end{array} & \begin{array}{c}\text { Ach. dendriticus } \\ \text { Bergey et al. }\end{array} \\ \begin{array}{l}\text { (Bordoni Uffre- } \\ \text { duzzi) Bergey } \\ \text { et al. }\end{array}\end{array}$

为 


\section{ACHROMOBACTER.}

$\begin{array}{lc}\text { Morphology } & \begin{array}{c}\text { Rods, medium } \\ \text { length, stout, } \\ \text { rounded ends, } \\ \text { occasional long } \\ \text { fi l a m e n s. } \\ \text { Gram-negative. } \\ \text { Motility }\end{array} \\ \text { Agar Slope } & \begin{array}{l}\text { Creamy, opaque, } \\ \text { slightly raised, } \\ \text { smo ot h and } \\ \text { shining surface. }\end{array}\end{array}$

Glucose

Lactose

Saccharose

Mannite

Dulcite

Indole

V.P.

Nitrate

Litmus Milk

No change.

Potato

No growth.

Gelatin

Slime

Intestine

Related to
20.

Spheres, singly and in pairs. Gram-positive.

-

emon - yellow, raised, opaque, $1 \mathrm{uxuriant}$, smooth shining surface.

+ faint or -

$$
\text { - }
$$$$
\text { - }
$$$$
-
$$

Coagulation, peptonisation,

litmus partially

reduced, serum

purplish brown.

Lemon - yellow, opaque, potato slightly

$\overline{+}$

$$
\begin{aligned}
& + \\
& + \\
& -
\end{aligned}
$$

\section{MICROCOCCUS.}

21.

Spheres, small, in pairs. Gram positive.

Lemon - yellow, raised, opaque, moist, smooth shining surface.

\section{+ faint or -}

Scanty, lemonyellow.

Scanty, lemon-
yellow.

Micrococcus subflavus Bumm.

$$
22 .
$$

Spheres, small, many slightly oval, in pairs. Gram-positive. opaque, slightly raised, moist, becoming tough.

$$
\begin{array}{r} 
\\
\text { late } \\
\text { late } \\
\\
- \\
- \\
- \\
+
\end{array}
$$

Faintly acid late.

Micrococcus ochraceus Rosen-
Pale lemon,

Alkaline.

Lemon - yellow, raised, opaque, $1 \mathrm{u} \times \mathrm{ur}$ i n . moist, smooth surface.

+
-
+
+
-
-
-
+

Scanty, lemonyellow. thal.

$$
\begin{aligned}
& + \\
& + \\
& -
\end{aligned}
$$

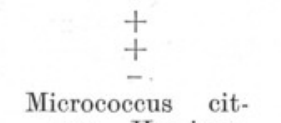
reus Harrison, Micrococeus conglomeratus Migula.

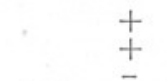

Micrococcus var ians Harrison, Micrococcus percitreus Bergey et al.
24.

Spheres, occur singly and in clumps. Gram positive.

Apricot, slightly raised, opaque, moist, smooth shining surface, becomes tough.

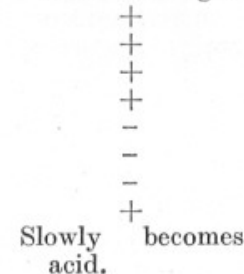
acid.

Scanty, orange.

Micrococeus au rantiacus Harrison, Micrococcus perflavus Bergey et al. 


\section{MICROCOCCUS.}

Morphology$$
25 .
$$

$$
26 .
$$

Spheres, singly, in pairs and clumps. Gram. positive.

Motility

Agar Slope

Porcelain - white, slightly raised, opaque, smooth surface, waxy. shine.

pheres, occurring in $\mathrm{clumps}$. Gram-positive.

+
+
+
-
-
-
+
+

Acid with or with. out coagulation.

No change.

Wite, flat, opaque, surface smooth and shining.

and

Glucose

Saccharose

Mannite

Dulcite

Indo

Nitrate

Litmus Milk

Potato

Porcelain-white, opaque, limited.

White, scanty.
No growth.

\section{7} occur in pairs and clumps of four. Gram positive.

$$
+
$$

Apricot, slightly raised, opaque, surface smooth, shining, becomes translucent.

+ or -

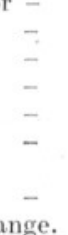

+
+
-

Spheres, large,

FLAVOBACTER.

Rods, short, aver- Rods, short and

Apricot, slightly

Gelatin

Slime

Intestine

Related to

-
+
-
Micrococcus can-
didus Harrison. age thickness, rather stout, occur singly. some slightly Gram - positive curved, occas. in very young ional long rods. culture. raised, opaque, surface smooth and shining, becomes tough.

Gram-positive.

Apricot, slightly raised, opaque, smooth and shining surface, becomes tough.

$$
-
$$

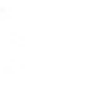$$
+
$$

Alkaline, slow peptonisation and reduction of litmus.

L u x u riant, apricot, opaque, moist.

30.

Rods, varying in length, some with swollen ends. Gram. positive in very young culture.

Lemon - yellow, slightly raised, opaque, surface smooth, later wrinkled into folds.

+ faint or -

Alkaline, slow peptonisation and partial reduction.

L u x u ria n t, opaque, apricot, moist.

$$
\begin{aligned}
& + \\
& + \\
& -
\end{aligned}
$$

Flavobacterium $\mathrm{m}$ a rin u m Harrison, N.Sp., Flavobacterium lutescens (Lustig)

Flavobacterium fucatum Harrison, N.Sp.

Alkaline, later peptonisation and partial re duction of lit mus.

Yellow, opaque, raised, moist, surface smooth and shining.

$$
\begin{aligned}
& + \\
& + \\
& -
\end{aligned}
$$

Flavobacterium turcosum Harrison.
必

党

Bergey et al. 
Morphology 31.

Rods, medium length, slender. Gram-positive.

Yellowish - green, flat, semiopaque, moist, surface smooth and shining.

\section{Glucose}

Lactose

Saccharose

- Mannite

Dulcite

Indole

V.P.

• Nitrate

is Litmus Milk

$\begin{aligned} & \text { Faint }+ \\ &- \\ & \text { Faint }+ \\ & \text { Faint }+ \\ &- \\ &- \\ &- \\ & \text { Faintly acid. }\end{aligned}$

Potato

\section{Greenish - yellow,} moist and shining, flat.

\section{2}

Gelatin

$\forall \quad$ Slime

Intestine

Related to
FLAVOBACTER.
Rods, medium size. Gram-negative.

\section{$+$}

Golden, flat, trans. lucent growth, surface smooth and shining.

$$
\begin{aligned}
& + \\
& - \\
& + \\
& + \\
& - \\
& - \\
& - \\
& +
\end{aligned}
$$

Acid with or without clot, peptonisation, reduction of lit-

$$
\text { mus. }
$$

Pale golden, wet, $\mathrm{s}$ p r e a ding growth, pigment deepens.

33.

Rods, short and slender, occasional long forms. Gram-positive.

\section{Alkaline, later partial peptoni- sation.}

Spreading, lemon, opaque, flat.

$$
\begin{aligned}
& + \\
& + \\
& -
\end{aligned}
$$

Flavobacterium dif- Flavobacterium fusum Harrison, sulphureum Flavobacter rigensis Bergey et al. Bergey et al.

\section{BACTLLUS.}

dovobacterium

son.
35 .

Rods, average size, rounded ends, spores long, oval, narrow. Gram-positive.

+

Flat, translucent, wet, creamy and opaque at foot of slope, surface smooth.

$$
\begin{aligned}
& + \\
& - \\
& + \\
& + \\
& - \\
& -
\end{aligned}
$$

Coagulation and peptonisation.
Litmus reduced.

B rown, wet, opaque, spreading, shining, potato dis coloured.

Rods, long, stout with square ends, spores oval, bulging bacillus, eccen tric to sub terminal. Gram.

Creamy, wet, sprea ding. raised, surface

\begin{tabular}{|c|c|}
\hline- & $\begin{array}{l}+ \\
- \\
- \\
- \\
-\end{array}$ \\
\hline $\begin{array}{l}{ }^{+} \text {Becomes slowly } \\
\text { alkaline and } \\
\text { peptonised. }\end{array}$ & $\begin{array}{l}\text { Peptonisation, lit- } \\
\text { mus reduced, } \\
\text { serum brown- } \\
\text { ish. }\end{array}$ \\
\hline $\begin{array}{l}\text { Raised, opaque, at } \\
\text { first smooth, } \\
\text { later wrinkling } \\
\text { into folds, fawn }\end{array}$ & $\begin{array}{l}\text { Opaque, dull } \\
\text { uneven surface, } \\
\text { ereamy becom- } \\
\text { ing fawn. }\end{array}$ \\
\hline
\end{tabular}
shining and smooth, later becomes uneven. 36.

Rods, long, stout, square ends, occur in chains, spores oval, subterminal bulge bacillus. Gram - positive show granules.

Creamy, flat, opaque, dull uneven surface. becoming pink. ish.

+
$\frac{+}{+}$
Bacillus mesensulphureum tericus Trevisan.
$+$ $+$
Bacillus sublana- tus Wright.

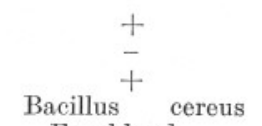

Frankland. positive. 


\section{LUMINESCENT CULTURE.}

\begin{tabular}{|c|c|}
\hline Morphology & $\begin{array}{l}\text { Rods, vary } \\
\text { morpho } \\
\text { many } \\
\text { others } \\
\text { itely bac } \\
\text { short and } \\
\text { some shov } \\
\text { ginal st } \\
\text { Gram-neg }\end{array}$ \\
\hline $\begin{array}{l}\text { Motility } \\
\text { Agar Slope }\end{array}$ & $\begin{array}{c}+ \\
\text { Translucer } \\
\text { semi - } \\
\text { slightly } \\
\text { smooth } \\
\text { surface, } \\
\text { ous. }\end{array}$ \\
\hline Glucose & + \\
\hline Lactose & - \\
\hline Saccharose & - \\
\hline Mannite & - \\
\hline Dulcite & - \\
\hline Indole & - \\
\hline V.P. & + \\
\hline $\begin{array}{l}\text { Nitrate } \\
\text { Litmus Milk }\end{array}$ & No change. \\
\hline Potato & No growth. \\
\hline Gelatin & - \\
\hline & + \\
\hline ntestine & \\
\hline
\end{tabular}

